\title{
Effect of Coarse Particle Volume Fraction on the Yield Stress of Muddy Sediments from Marennes Oléron Bay
}

\author{
A. Pantet, ${ }^{1}$ S. Robert, ${ }^{2}$ S. Jarny, ${ }^{3}$ and S. Kervella ${ }^{2}$ \\ ${ }^{1}$ Université du Havre, LOMC, FRE CNRS 3102 - 53, Rue Prony, BP540, 76058 Le Havre, France \\ ${ }^{2}$ IFREMER, LERPC, Place Gaby Coll, BP7, 17137 L'Houmeau, France \\ ${ }^{3}$ Université de Poitiers, LEA, UMR CNRS 6609, Boulevard M. et P. Curie, 86962 Futuroscope Cedex, France
}

Correspondence should be addressed to A. Pantet, anne.pantet@univ-lehavre.fr

Received 25 March 2010; Accepted 16 May 2010

Academic Editor: Marcel Ausloos

Copyright (C) 2010 A. Pantet et al. This is an open access article distributed under the Creative Commons Attribution License, which permits unrestricted use, distribution, and reproduction in any medium, provided the original work is properly cited.

\begin{abstract}
Coastal erosion results from a combination of various factors, both natural and humaninduced, which have different time and space patterns. In addition, uncertainties still remain about the interactions of the forcing agents, as well as on the significance of non-local causes of erosion. We focused about the surface sediments in the Marennes Oléron bay, after a general description of the site that has many various activities. The superficial sediments show a mechanical behavior, mainly depends on the fine fraction for a composition that contains up to $60 \%$ of sandy material. Fine sediments fraction has a typical yield stress depending naturally of concentration or water content. This yield could be modified slightly or significantly by adding silt or sand. As a result, the rheological measurement sensitivity allows us to characterize five typical sediments that correlate with solid fraction and fine fraction.
\end{abstract}

\section{Introduction}

Heterogeneous systems consisting of particles suspended make up a wide variety of materials, both natural as slurries, debris flows, and sediments or man made such as cements, paints, and pastes. The main difficulty comes from the fact that the materials are heterogeneous, with many interacting components.

In this paper, we focus on natural suspensions represented by sediments located in the Marenne Oléron bay $(\mathrm{MOb})$. Experimental data are presented on the overall rheological properties of the sediments which depend on the size of the particles, the interaction between particles (colloidal and non colloidal), the interaction between particles and suspending fluid, the properties of the suspending fluid, and conditions of flow.

We present the general context and explain why the knowledge of the intertidal zones is important for the ecosystem production. During the last century, an increasing anthropogenic pressure near the littoral coasts has been observed, namely, building and land occupation and agricultural and industrial activities. In addition, the increase of conchylicultural activities has resulted in a significant change of its morphology, influencing the water circulation and quality [1]. In the coastal and estuarine turbid waters, interactions between waves, current, mud, and turbulence are very complicated and have an effect on the light penetration which directly influences the production.

The movements of suspended sediments in estuaries and coastal environments cause many problems which can be broadly classified into two categories. The first relates to erosion, transport, and deposition processes and the consequences for development of the bay. The second refers to the role of the fine, especially cohesive, sediments in the transport of contaminants or the nutrient or the chemical compounds transported in the suspended phase.

This paper presents a measurement standardisation from data collected in the bay, to understand the rheological properties. Indeed, the network structure of sediment mixture is determined by the relative proportions of sand, silt, and clay particles. Differences in erosion behaviour can be expected when the network structure changes from sand-dominated in silt-dominated or clay-dominated particle mixtures. The state of the sediments (loose or dense) depends on the 
water content. For high water content, the distance between the particles becomes larger, and the contact between the particles decreases (loose packing). Geometric patterns at the surface of mud layers are attributable to changes in the rheological characteristics that accompany changes in water content, as a result of the change of dominance of frictional resistance of particles to cohesion. Muddy layers are predominantly eroded directly into suspension whereas sand layers are mainly eroded into bed load. Furthermore, for purely consolidated cohesive beds large aggregates or lumps of materials are being transported mostly as bed load [2].

\section{Study Area}

The study area, Marennes Oléron bay, is located at the west of France. This tidal flat area is $150 \mathrm{~km}^{2}$, where the surfaces of sediments are dominated by sand at the west and a large mud deposits at the east. The tides are semidiurnal with a mean range of $6 \mathrm{~m}$. Current velocities vary from $0.6 \mathrm{~m} \cdot \mathrm{s}^{-1}$ on the intertidal zone to $1 \mathrm{~m} \cdot \mathrm{s}^{-1}$ in the main channel. Current directions on the flats can vary. Wind waves are generally lower than $0.80-1 \mathrm{~m}$ over the upper tidal flats.

For the study, a large in situ field has been practised by IFREMER. Field work to obtain comprehensive data sets is even more expensive. To complete with large investigation, 220 samples have been collected in many places of the Marennes Oléron bay, located on Figure 1.

Care was taken to only sample the uppermost $2 \mathrm{~cm}$ of the tidal flat, which corresponds to the active zone, when the sediments are resuspended regularly.

We have studied the rheological behaviour of the sediment deposited just after the immersion beginning. Three levels have been collected manually $(0-0.5 \mathrm{~cm}, 0.5-1 \mathrm{~cm}$, and $1-2 \mathrm{~cm})$. Water-bed exchange processes in the marine environment are governed to a large extent by the erodibility of the upper few $\mathrm{mm}-\mathrm{cm}$ of the bed.

\section{Materials and Methods}

Sediment is a mixture of a solid phase consisting of granular particles sizing in the range from mm's to particles less than $1 \mu \mathrm{m}$ that can form flocs. Particles size, solid density, and particle shape are the dominant parameters influencing mechanical properties.

3.1. Grain Size Distribution and Water Content. Grain size distribution of muds has been made with an automatic laser apparatus Beckman Coulter LS 13320; the samples were diluted in saline water, without specific dispersant.

We define three characteristic fractions: sand fraction $(\varnothing>50 \mu \mathrm{m})$, silty fraction $(50 \mu \mathrm{m}>\varnothing>2 \mu \mathrm{m})$, and clayey fraction $(\varnothing<2 \mu \mathrm{m})$. The size fraction comprising silt and clay is known as mud or fines. Only the clay particles within the mud fraction have cohesive properties.

The sediment water content $(\mathrm{w} \%)$ was calculated as follows:

$$
\mathrm{w} \%=\frac{\mathrm{wt}_{\mathrm{wet}}-\mathrm{wt}_{\mathrm{dry}}}{\mathrm{wt}_{\mathrm{wet}}} * 100
$$

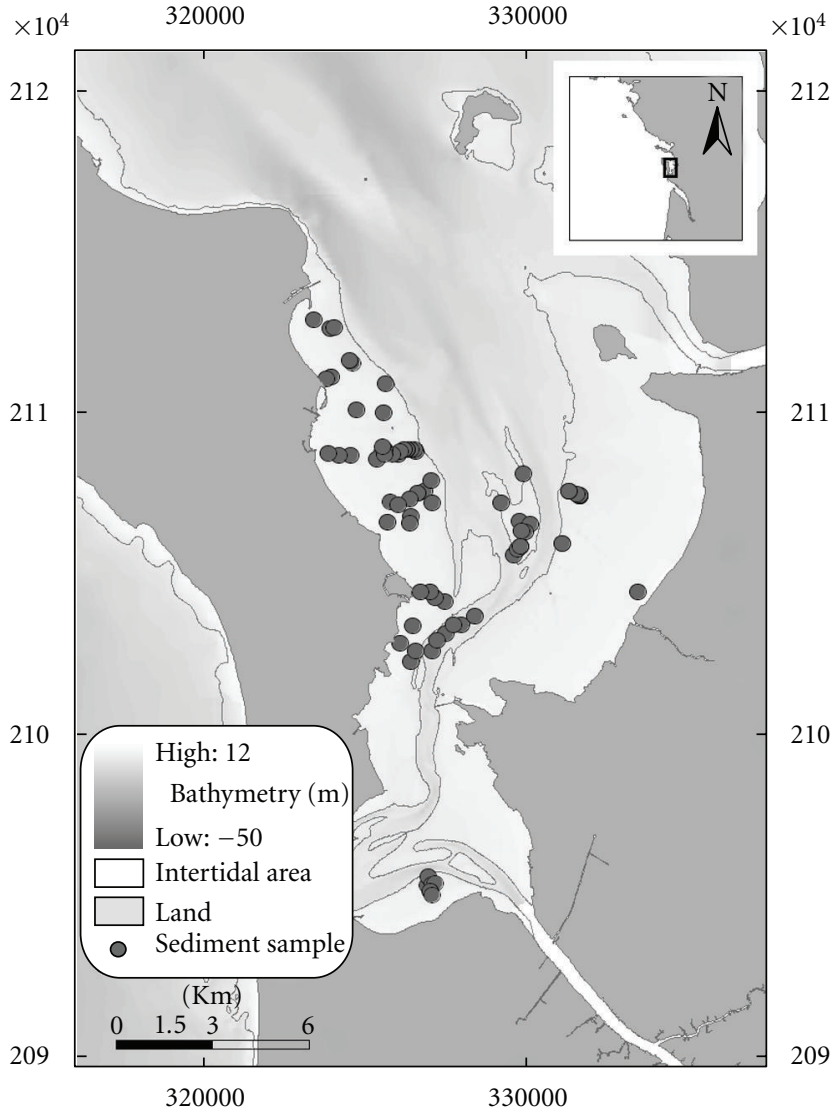

Figure 1: Location of studied areas in the Marennes Oléron bay.

where $\mathrm{wt}_{\mathrm{wet}}$ is the sediment weight and $\mathrm{wt}_{\mathrm{dry}}$ the dryed sediment weight obtained at $60^{\circ} \mathrm{C}$ for $24 \mathrm{~h}$.

Consequently, the volume concentration of total solids $(\phi)$ named also solid fraction is determined with solid volume $\left(V_{s}\right)$, total volume $\left(V_{t}\right)$, water content $(\mathrm{w}$,$) and solid$ density $\left(\rho_{s}\right)$ :

$$
\phi=\frac{V_{s}}{V_{t}}=\frac{1}{1+\rho \cdot w} .
$$

3.2. Rheological Analysis for the Suspensions. A Physica MCR 301 controlled stress rheometer with plate geometry was used to achieve rheological data for the sediments suspensions. Every test started with a manual mixing to homogenize and remove some peaces of shells. Experimental flow curves were obtained with rough parallel-plate geometry (diameter $50 \mathrm{~mm})$ spaced $1 \mathrm{~mm}$ apart. A preshear was imposed $\left(10 \mathrm{~s}^{-1}\right.$ for $60 \mathrm{~s}$ ) followed by a rest period (60s) before each test in order to put the dispersion in an initial structural state. Then, dispersions were subjected to increasing and decreasing shear rates leading to a hysteresis loop between the flow curves. Experiments were repeated at least three times for each sample to ensure repeatability.

It exist many definitions of yield stress. Defining yield stress as the threshold for the beginning of the motion is widely accepted [3]. Indeed yielding is associated with 
TABLE 1: Measurements data.

\begin{tabular}{lcccccc}
\hline Samples & Mean & Sd & Se & Min $Y$ & Max $Y$ & range \\
\hline [220] sand (\%) & 46,84 & 21,92 & 1,48 & 0,00 & 88,00 & 88,00 \\
[220] Yield stress Pa & $116,4964,77$ & 4,37 & 9,56 & 320,00 & 310,44 \\
[220] Water content (\%) & 76,68 & 41,77 & 2,82 & 31,00 & 249,00 & 218,00 \\
\hline
\end{tabular}

several complex processes such as particles arrangement and dynamics of particles contacts, depending of the material history. Clearly the definition of yield stress will be influenced by the technical apparatus and scale of processes being investigated.

The yield stress values $\left(\tau_{y}\right)$ are taken by the value corresponding at the low shear rate $0,1 \cdot \mathrm{s}^{-1}$ on the decreasing flow curve. It is a restoring yield value.

For coarse sediments, some sources of trouble migration, segregation, fracturation, flow heterogeneities, shear banding, evaporation, sliding wall, and so forth are observed. So only with samples with sand content $<60 \%$ are tested. These experimental problems demonstrate that the bulk behaviour of natural material is characterised by wide fluctuations, for example, jamming in the particle network for concentrated materials, dilatancy-contraction effects, aging, and chemical alteration (organic matters degradation, exchange between the constituents, etc.).

\section{Experimental Results}

In this section, we summarize the results of measurements performed on the sediment with the procedure presented above. The collections were made between 2005 and 2008.

Table 1 gives for a general analysis the statistical data obtained directly with 220 samples collected in many places of the Marennes Oléron bay.

4.1. Size Distribution of the Sediments. Size distribution of the sediments (only the superficial sediments, $\max 2 \mathrm{~cm}$ ) shows a high variability depending on the location; the occidental intertidal zones are sandy and the east intertidal zone (Brouage) is muddy flat, the central zone depending on the season, either sandy in winter or muddy in summer.

Grain-size frequency distribution was established and compared with the triangular diagram showed by Van Ledden et al. [4], where they defined a domain of cohesive and noncohesive mixtures (Figure 2). The transition ranges between $5 \%$ and $10 \%$ clay content.

They distinguished three types: cohesive sand dominated, cohesive clay dominated, and cohesive silt dominated. The dependence on the water content are also underlined.

All the results are represented in the triangular diagram. It clearly appears that all samples of sediments is organized on one line, which indicates that the silt fraction on clay fraction ratio is constant with a value of 0.15 . This was observed already by van Ledden et al. [4] for the Western Scheldt (Netherlands) with the same ratio of 0.25 .

This relation, often observed in littoral environment, is interpreted as a condition of similar transport for of clay and silt particles together.

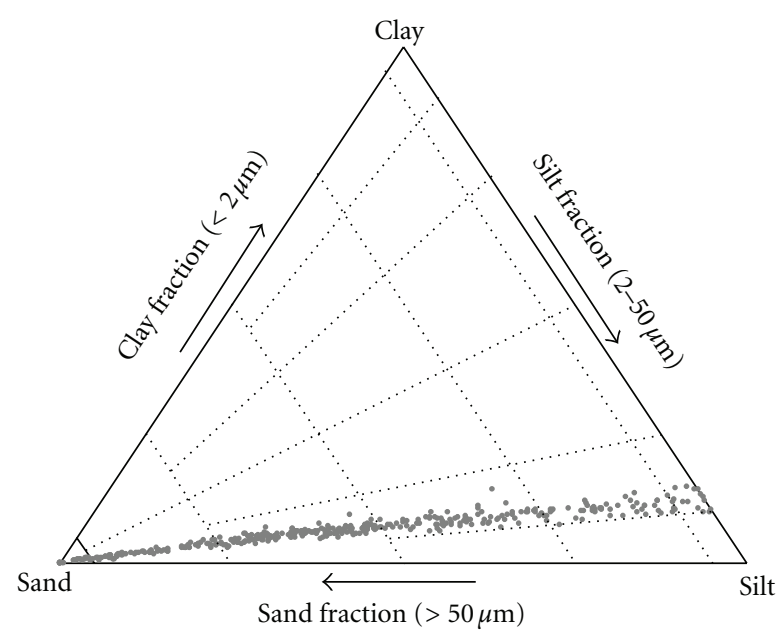

FIgURE 2: Triangular diagrams of Flemming textural classification. (a) first sampling level $(0-1 \mathrm{~cm})$; (b) second sampling level $(1-2 \mathrm{~cm})$.

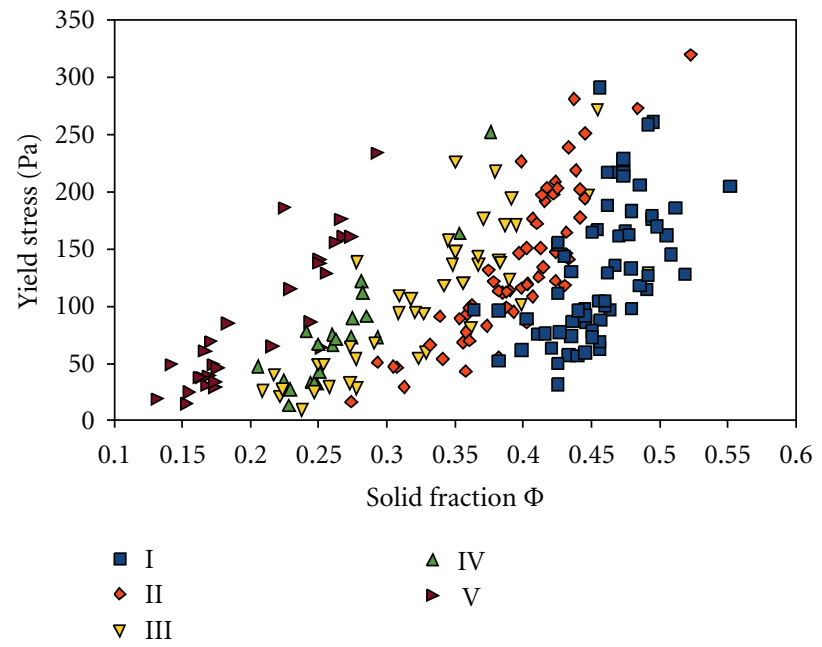

FIGURE 3: Relation between solid fraction sediments and yield stress for the 5 types.

TABLE 2: Five types of sediments in MOb.

\begin{tabular}{lcccc}
\hline \multirow{2}{*}{ Sediment type } & \multirow{2}{*}{ Rheological type } & \multicolumn{3}{c}{ Fraction (\%) } \\
& & Sand & Silt & Clay \\
\hline Silty sand & I & $75-60$ & $21-34$ & $4-6$ \\
Muddy sand & II & $60-45$ & $34-46$ & $6-9$ \\
Sandy mud & III & $45-29$ & $46-61$ & $9-10$ \\
Slightly sandy mud & IV & $29-18$ & $61-71$ & $10-11$ \\
Mud & V & $18-0$ & $71-81$ & $11-13$ \\
\hline
\end{tabular}

4.2. Mechanical Properties. Yield stress $\tau_{y}$ is defined as the stress value at strain rate value equal to $0.1 \cdot \mathrm{s}^{-1}$ on the decreasing curve of the rheogram, when the shear rate decreases. Sediments yield stresses are then classified as a function of solid fraction distribution size, in Table 2.

The comparability of the large data collected allows us to define five types of mixed sediments, establishing the relation between the texture and concentration parameters with the yield value in Figure 3. 


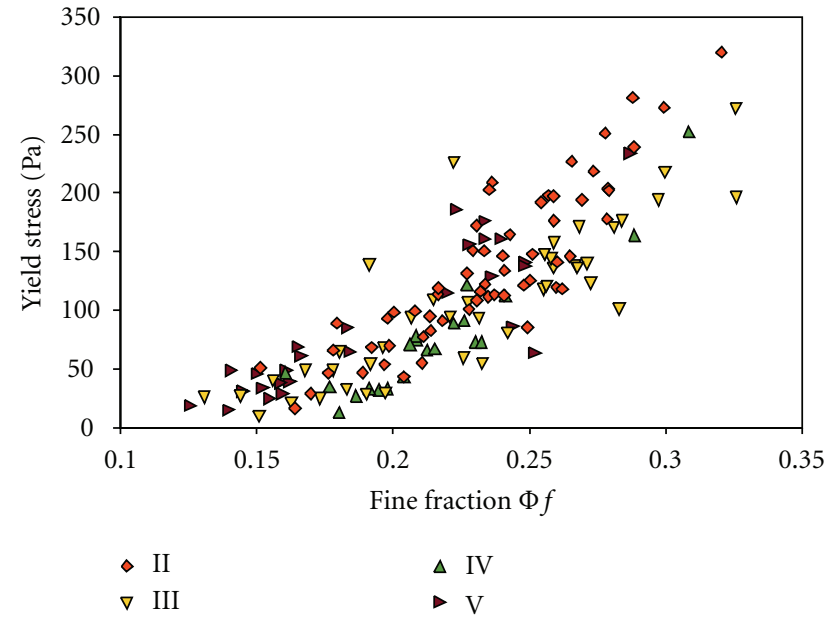

Figure 4: Relation between fine fraction and yield stress of $\mathrm{MOb}$ sediments.

To precise the coarse particles effects within mud, results have been examined considering the ratio of fine fraction on solid fraction by using these formulas. For all samples, from the total solid fraction $\phi=\left(V_{f}+V_{g}\right) /\left(V_{w}+V_{f}+V_{f}+V_{g}\right)$ and the fine/solid fraction $\psi=V_{f} /\left(V_{g}+V_{f}\right)$, we calculate the fine/fine in the water ratio and the grains fraction in the mixture:

$$
\begin{gathered}
\phi_{f}=\frac{V_{f}}{V_{f}+V_{w}}=\frac{\psi}{\psi-1+1 / \phi}, \\
\chi=\frac{V_{g}}{V_{w}+V_{f}+V_{g}} .
\end{gathered}
$$

Finally, all the data are gathered together in Figure 4, where the yield stress is represented as a function of the fine/fine in water ratio. Then a power law, expressed as follows $\tau_{y}=$ $A\left(\phi_{f}\right)^{N}$ is fitted on the data leading to $N=3$.

Migniot [5] had also applied a power law expression for muddy sediment such as $\tau_{y}=b C^{a}$, with $a=6$ and $b$ a constant for each sediment ranging from $2,4 \cdot 10^{-15}$ to $21 \cdot 10^{-15}[6]$.

For the families II to V, a good correlation is observed on the overall data, so we can used it to establish the relations when sand is added progressively to obtain a ternary mixture grain in a fine-water suspension [7-9]. Similar approach has been used for cement paste mixed with sand [10].

Finally by using the Krieger Dougherty approach, theoretical yield stress for the mixture grain and clay-water system or ternary mixture can be evaluated:

$$
\tau_{y}=A \cdot\left(\cdot \phi_{f}\right)^{N} \cdot\left[1-\frac{\chi}{\phi_{m}}\right]^{-M}
$$

with $M$ a positive coefficient and $\chi=\phi \cdot(1-\psi)$ the grains fraction in the mixture.

The solid concentration of coarse particles is very close to the maximum concentration $\phi_{m}$ (the maximum packing solid fraction) assumed equal to 0.635 . Grains or coarse particles are supposed to be not deformable and not porous; only hydrodynamic interactions are possible.

The result shows that the bulk yield stress may be significantly affected by concentration of coarse particles; however fine fractions have always an important effect. The fine sediments fraction in Marennes Oleron bay shows a typical yield stress depending naturally on either the particles concentration or the water content. This yield stress can be modified slightly, but significantly, by adding silt or sand. However when yield stress of the fine-water suspension is still high, the modification occurs more moderately. Coarse fraction is assumed to act independently of the fine fraction.

Figure 5 shows the effects of sand adding, in an interstitial fluid defined with a concentration and a yield stress. The lines are the theoretical expression of the KriegerDougherty formula. When grains are added to a sufficiently concentrated fine-water system, which have a yield stress, the behaviour became more complex, and also the measurements. When noncolloidal particles are added, fraction of interstitial fluid in a given volume decreases. In our case, yield stress increases when adding sand like adding fine, though these two particles types interact quite differently with water. This suggests that the fine water system remains the prime factor affecting the suspension behaviour. This is acceptable, for low or moderate fractions of added grains, because the number of direct contacts between the grains is negligible.

Bulk yield stress may be significantly affected by the concentration of coarse particles, but its features are still governed by the fine colloidal fraction.

Figure 6 shows the conceptual rheological classification of water-sand mixtures for each type of material. Many zones of distinct behaviour are defined.

(i) Zone A, muddy solid, because with high solid grain concentration, no flow is possible.

(ii) Zone B in this zone, an immediate settling of the coarsest particles takes place at rest so nonhomogenous fluid.

(iii) Zone C: In this zone, the mass behaviour is essentially controlled by the interstitial fine particle water mixture behaviour. The flow curve can be well represented by a Herschel-Bulkley model.

(iv) Zone D: in this transitional zone, the maximum grain packing concentration is not reached but a slow or rapid flow cannot take place without fracture.

\section{Conclusions}

Fine sediments fraction in Marennes Oleron bay has a typical yield stress depending naturally on concentration or water content. This yield could be modified slightly or significantly by adding silt or sand. However, when the yield stress of the clay-water suspension is still high, modifications increase more moderately.

As a result, the rheological measurement sensitivity allows us to characterize five typical sediments that correlate with solid fraction and fine fraction. 


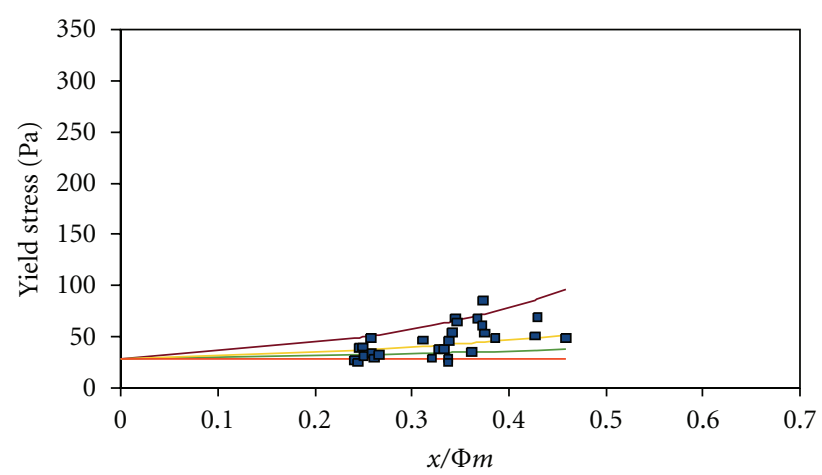

- Yield stress measured $-M=2$

- $M=0.5 \quad-M=1$

Fine yield stress

(a)

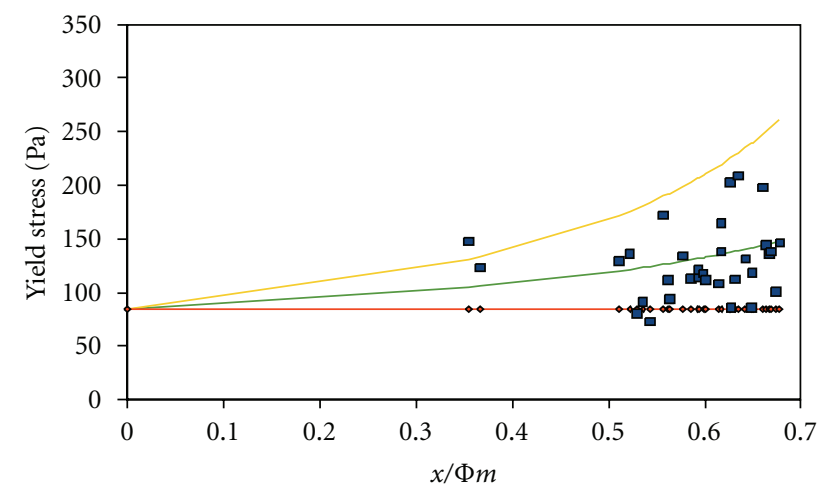

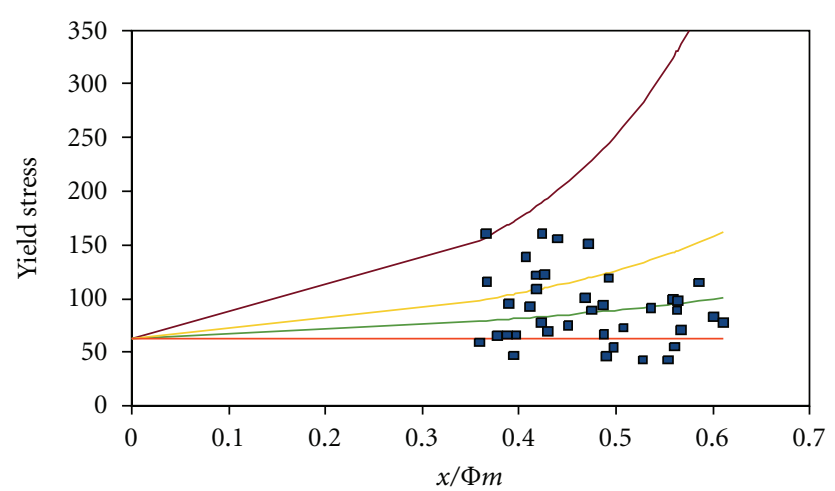

- Yield stress measured $-M=2$ $M=0.5 \quad M=1$ Fine yield stress

$$
\begin{aligned}
& \text { - Yield stress measured } \quad-M=1 \\
& \therefore \text { Fine yield stress } \quad M=0.5
\end{aligned}
$$

(b)

(c)

Figure 5: Relation between granular fraction of the interstitial fluid (fine water).

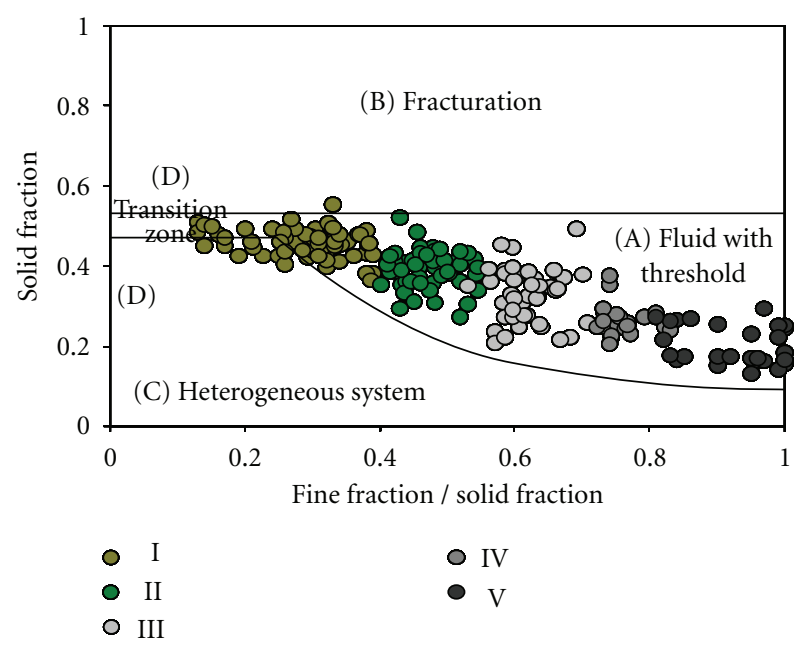

FIGURE 6: Conceptual scheme for the five types of MOb sediments.

Sediment is a complex mixture, with different phases, more or less saturated, exhibiting a large scattering of the rheological parameters.
The examination of various interactions demonstrates that the evolution is directly linked with the interstitial fluid and the solid fraction due to the shear-induced contact lubrification. However the effects of the size of the particles are not still introduced, lacking of detailed data.

\section{Acknowldgment}

The authors wish to thank the Conseil Général de la Charente Maritime and IFREMER.

\section{References}

[1] S. Robert, P. Le Hir, and O. Le Moine, "Étude pour une gestion dynamique des sédiments sur les côtes du bassin de MarennesOléron et le pertuis de Maumusson," Rapport IFREMER 4, Conseil Général de Charente-maritime, 2006.

[2] H. Mitchener and H. Torfs, "Erosion of mud/sand mixtures," Coastal Engineering, vol. 29, no. 1-2, pp. 1-25, 1996.

[3] Ph. Coussot, Mudflow Rheology and Dynamics, IAHR Monograph, Taylor \& Francis, London, UK, 1997.

[4] M. van Ledden, W. G. M. van Kesteren, and J. C. Winterwerp, "A conceptual framework for the erosion behaviour of 
sand-mud mixtures," Continental Shelf Research, vol. 24, no. 1, pp. 1-11, 2004.

[5] C. Migniot, "Etude des propriétés physiques de différents sédiments très fins et de leur comportement sous des actions hydrodynamiques," La Houille Blanche, vol. 7, pp. 591-620, 1968.

[6] M. Sanchez and Y. Delanoé, "Dynamique sédimentaire des estuaires," Revue Française de Génie Civil, vol. 5, no. 7, pp. 1067-1084, 2001.

[7] C. Ancey and H. Jorrot, "Yield stress for particle suspensions within a clay dispersion," Journal of Rheology, vol. 45, no. 2, pp. 297-319, 2001.

[8] C. Ancey and Ph. Coussot, Rhéophysique des pâtes et des suspensions, EDP Sciences, 1999.

[9] G. K. Batchelor, "The stress suspension in a suspension of freeforces particles," Journal of Fluid Mechanics, vol. 41, no. 3, pp. 545-570, 1970.

[10] F. Mahaut, X. Chateau, Ph. Coussot, and G. Ovarlez, "Yield stress and elastic modulus of suspensions of noncolloidal particles in yield stress fluids," Journal of Rheology, vol. 52, no. 1, pp. 287-313, 2008. 

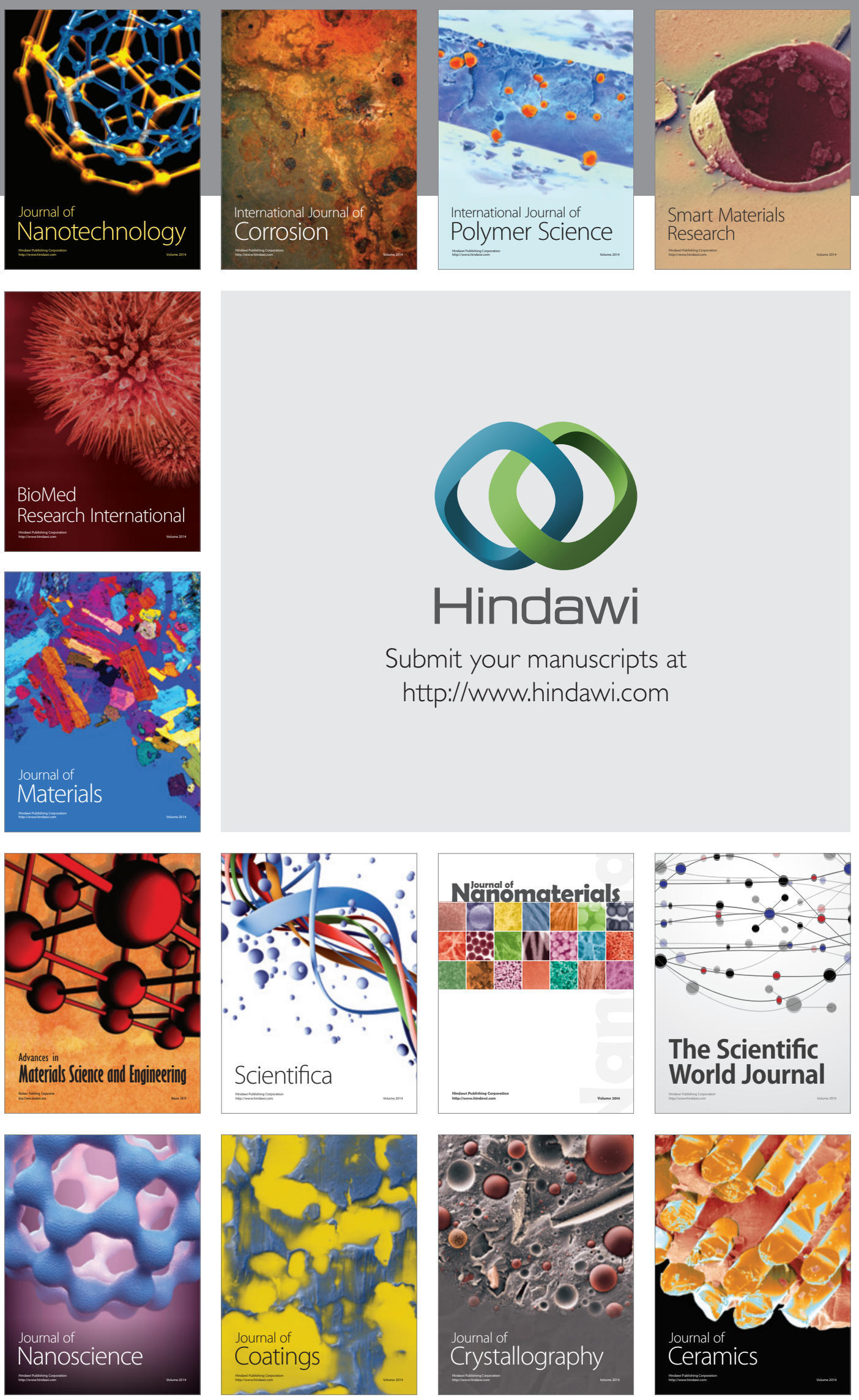

The Scientific World Journal

Submit your manuscripts at

http://www.hindawi.com

\section{World Journal}

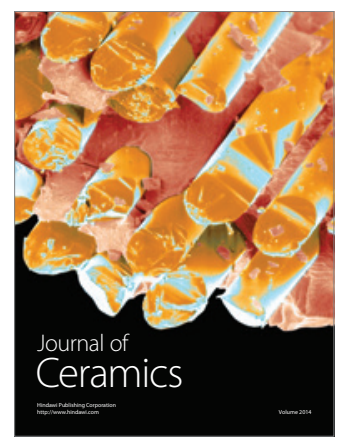

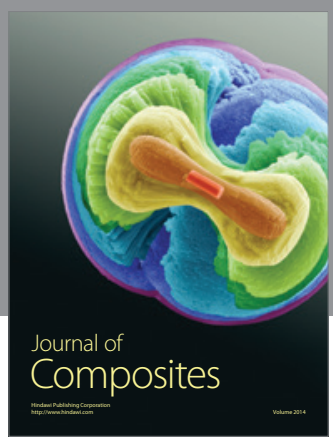
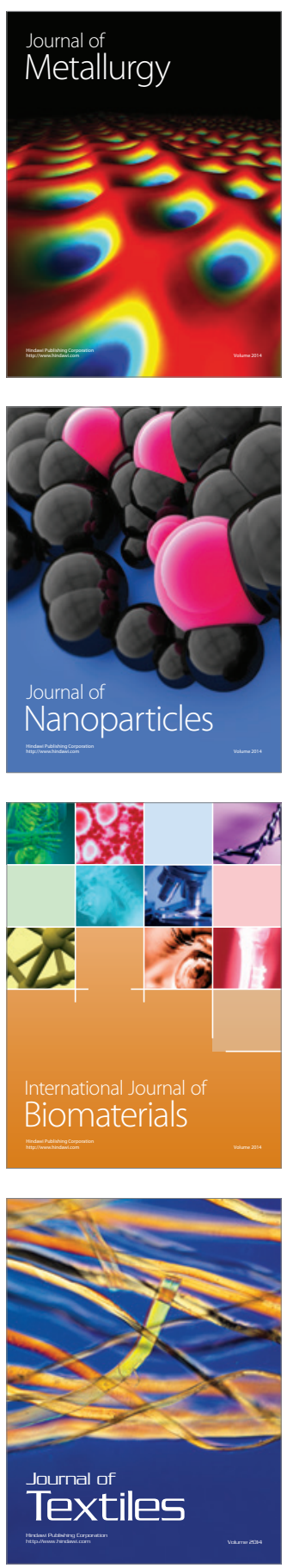